In the searching of bringing new meanings to personal biography, some people affected by the broken up of a cesium-137 teletherapy unit, in Goiânia, became the disaster memory-guardian. Among the private archives established, Luiza Odete 's files are a case in point due to a postcards collection of urban landscapes, gathered when she was as a secluded patient at Naval Marcilio Dias Hospital, in Rio de Janeiro. Based upon the analysis of this collection and on the data from interviews made with the collection owner, this paper addresses the following questions: in the context of segregation, which place/es a person builds when looking at Rio de Janeiro tourist images? Why collect postcards as a disaster radiation victim?

Key-Words: post-cards; traumatic memory; radiation disaster 


\section{Colecionando Cartões Postais: Os Lugares Constituídos Em Contexto De Isolamento}

Telma Camargo da SILVA

Na procura da re-significação da biografia pessoal, algumas pessoas atingidas pela radiação decorrente da ruptura de um aparelho de radioterapia, contendo césio-137, em Goiânia, se tornaram guarda-memória do desastre. Entre os arquivos pessoais assim construídos, o acervo de Luiza Odete se destaca por conter uma coleção de cartões postais de paisagens urbanas, reunida em 1987, quando ela estava isolada no Hospital Naval Marcílio Dias, no Rio de Janeiro. A partir da análise desta coleção e de entrevistas orais com a colecionadora, este texto discute as seguintes questões: que lugar/es se constrói, em contexto de segregação, o olhar pousado sobre uma coleção de imagens turísticas do Rio de Janeiro? Por que colecionar cartões postais enquanto vítima de um desastre radioativo?

Palavras-chave: cartões-postais; memória traumática; desastre radioativo. 


\section{Introdução}

Durante o meu trabalho de campo (1996 - 1997)' ${ }^{1}$, para a redação da minha tese de doutorado sobre as representações de saúde e de doença e sobre a produção da memória no contexto do desastre radioativo de Goiânia, um fato me chamou a atenção: a constituição de acervos pessoais por parte das pessoas impactadas pela catástrofe. No processo de coleta de dados, que compreendeu o registro sonoro e visual de narrativas de múltiplos atores sociais, a construção de histórias de vida e a consulta a arquivos públicos, eu me deparei com estes acervos pessoais compostos por documentos escritos, iconográficos e sonoros.

Para alguns, como no caso dos policiais militares, que na época reivindicavam uma relação de causa e efeito entre sofrimento e trabalho realizado durante a emergência radioativa, colecionar documentos remetia à constituição de uma identidade de vítima da radiação. O pertencimento à rede social do desastre carecia de comprovação e neste contexto, os acervos pessoais se configuravam como suportes da memória testemunhal (SILVA, 1998, p. 117-138). Eram estas coleções de documentos que constituiam o elemento fundamental da performance desses indivíduos nos espaços públicos onde os relatos dos dramas sociais vivenciados em 1987 eram revividos: as reuniões da Associação de Cabos e Soldados, os encontros no Hospital da Polícia Militar do Estado de Goiás (HPM- Goiânia) e nas Audiências Públicas, no Congresso Nacional, em Brasília. Para outros, colecionar documentos, como recortes de jornais onde a notícia era o próprio colecionador, indicava que o curso 'normal' da vida havia sido interrompido, como já expresso através do processo de narrativização do desastre, e que a trajetória da catástrofe estava imbricada na história de vida do indivíduo afetado (SILVA, 2002). Contudo, o arquivo construído por Luiza Odete ${ }^{2}$ se diferenciava dos outros. Entre os vários tipos de documentos guardados havia uma coleção de cartões postais com imagens da cidade do Rio de Janeiro, formada por ela quando estava internada, enquanto paciente contaminada pela radiação, no Hospital Naval Marcílio Dias, localizado no Rio de Janeiro. Estas imagens do Rio turístico representado nos cartões postais e guardadas ao longo dos anos por uma pessoa vitimada pela exposição à radiação suscitou 
alguns questionamentos: 1) em contexto de isolamento, que lugar/ lugares, o olhar constrói quando pousado sobre uma coleção de paisagens urbanas? 2) Se, como aponta Ecléia Bosi, "a memória do indivíduo depende do seu relacionamento com a família, com a escola, com a Igreja, com a profissão, enfim com os grupos de convivência e os grupos de referência peculiares a cada indivíduo" (apud SA, 2007, p. 45), que memória do Rio de Janeiro se constrói através da sociabilidade vivenciada como paciente do Hospital Marcílio Dias? 3) Por que colecionar cartões postais de cenas urbanas enquanto vítima de um desastre radioativo?

Assim, este texto se propõe discutir e analisar a interligação entre $\mathrm{o}$ ato de colecionar cartões postais, a representação das imagens guardadas e a instituição da pessoa social, em contexto de desastre radioativo.

\section{A constituição da coleção de cartões postais: a biografia cultural dos objetos guardados e a narrativa da segregação}

Ao discutir o uso de fontes visuais, Meneses enfatiza a necessidade de examiná-las "mais do que como documentos, (vêlas) como ingredientes do próprio jogo social, na sua complexidade e heterogeneidade" (2005, p. 44). Nesta perspectiva, e ele acrescenta, as imagens têm uma dimensão de objeto, de artefato, que junto com a possibilidade aberta de identificar e interpretar os sentidos da linguagem visual contida na fotografia, faz-se necessário refletir sobre os contextos em que, nesse caso os cartões postais, se integram à vida social de quem os coleciona. É o levantamento da constituição do acervo que nos dará elementos para significálo na história de vida de um indivíduo: como, quando e porquê um conjunto de documentos se constitue como um acervo a ser guardado e conservado?

Antes de falarmos sobre os documentos guardados por Odete, vamos situá-la na rede social engendrada pelo desastre de Goiânia. Luiza Odete foi uma das primeiras pessoas a ter contato com a fonte radioativa. O material chegou até ela porque sua família morava no Ferro Velho do Ivo, seu primo e irmão de Devair, a 
pessoa que comprou a cápsula e a levou para o seu Ferro Velho. Nesse mesmo local, ficava a casa em que Devair morava e foi em sua residência e em seu local de trabalho que ele distribuiu partes do pó radioativo para membros de sua rede familiar e de amizade. Luiza Odete faz parte do grupo de pessoas que fascinada com o brilho de purpurina azul do césio-137 à noite, usou o material no corpo. Em conseqüência, ela não só foi irradiada e contaminada pela radiação, como também teve todas as partes do corpo que anteriormente haviam sido cobertas pelo brilho do césio, transformadas em radiodermites. O lado esquerdo do seu pescoço se transformou em uma grande ferida, com lesões perto da artéria. Foi nestas condições que alguns dias após o reconhecimento pela Comissão Nacional de Eneriga Nuclear (CNEN) do desastre de Goiânia como um desastre radioativo, o que aconteceu em 29 de setembro de 1987, ela integrou o segundo grupo de pessoas ${ }^{3}$ que foi transferido do isolamento no Hospital Geral de Goiânia (HGG) para o isolamento no Hospital Naval Marcílio Dias (HNMD) ${ }^{4}$, no Rio de Janeiro, onde ficou até início de dezembro de 1987. Este hospital militar era, segundo relatos, a única instituição hospitalar preparada, naquela época, para receber pacientes vítimas da síndrome aguda da radiação. Isto porque ele fazia parte do projeto secreto de construção do submarino atômico brasileiro, pelos militares. Ou seja, ele havia sido equipado e reestruturado com a construção de espaços projetados para atender uma possível emergência decorrente de catástrofes relacionadas ao projeto de construção do submarino nuclear brasileiro - "Projeto Remo" -, parte do chamado programa nuclear paralelo brasileiro, patrocinado pelas Forças Armadas ${ }^{5}$. Uma equipe de profissionais altamente qualificada em termos de medicina nuclear também fazia parte dos quadros do HNMD.

É pois no contexto do Hospital Naval Marcílio Dias, que o arquivo pessoal de Odete começou a ser constituído. Dessa época e enquanto paciente, ela guarda um conjunto composto de textos impressos de orações dadas pelo capelão do HNMD e a coleção de dezessete postais da cidade do Rio de Janeiro. Também fazem parte do seu acervo, vários recortes de jornais e documentos relacionados à presença dos filhos em Cuba, em 1992, quando se deslocaram para este país para receberem tratamento médico.

A coleção de cartões postais ${ }^{6}$, objeto de análise deste texto, 
retratam:

- Ponte Rio - Niterói ("Ponte Presidente Costa e Silva): um cartão;

- Vista aérea do Cristo Redentor: dois postais;

- Vista em contre-plogée do Cristo Redentor tendo à frente o Bondinho de Santa Theresa: um postal ;

- Teatro Municipal: um postal;

- Bondinho do Pão de Açúcar: um postal;

- Vista noturna do Rio: dois postais;

- Vista parcial do Pão de Açúcar e do Morro da Urca: um postal;

- Praia de Copabana com vista diurna e com banhistas: dois postais;

- Vista noturna da Baia de Guanabara, do Pão de Açúcar e do Morro da Urca um postal;

- Vista noturna de um velejador tendo ao fundo o Cristo Redentor: um postal;

- Vista noturna do mar, tendo ao fundo vista parcial da cidade do Rio: um postal;

- Vista diurna da orla da Zona Sul do Rio: dois postais;

- Vista do entardecer nos calçadões de Copacabana: um postal;

Dos dezessete cartões da coleção, onze postais não trazem nenhum texto no verso. Segundo Luiza Odete, eles Ihe foram dados no HNMD por duas integrantes do grupo de atendimento: Daise e Luiza. A primeira, funcionária do Instituto de Radioproteção e Dosimetria (IRD), assina duas das seis mensagens textuais. Estas duas mensagens são datadas (12/12/87) e, ao contrário dos cartões sem escrita no verso, indicam que foram enviados quando Luiza Odete já havia retornado a Goiânia.

Uma dessas mensagens indica que Luiza Odete embora tenha passado três meses no Rio de Janeiro não visitou a cidade: "Luíza (Odete), esta é uma das paisagens lindas da minha cidade. Infelizmente você não pode conhecer" (Imagem 1). A outra mensagem associa a iconografia do Cristo Redentor de braços abertos - representado em quatro postais da coleção - ao acolhimento de todos que acreditam e têm fé: "Luíza (Odete), tenha fé neste Cristo que está aberto para todos que crêem nele" 
(Imagem 2).

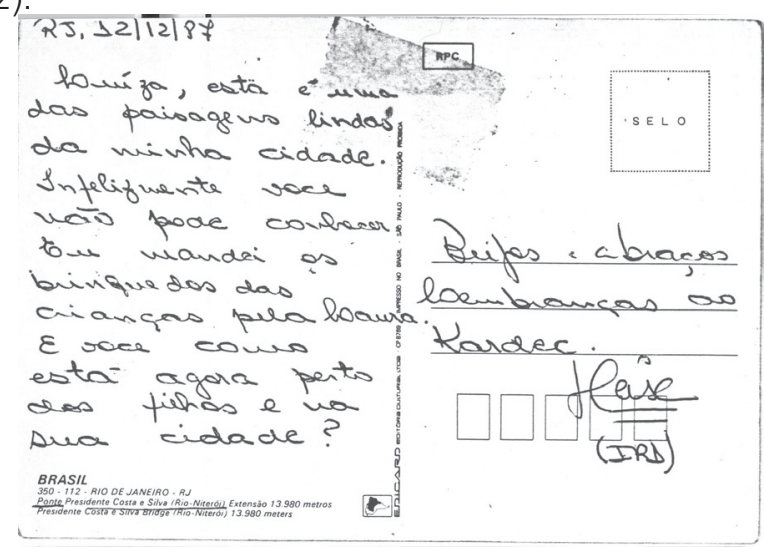

Figura 1 - Verso do cartão "Ponte Presidente Costa e Silva (Rio - Niterói)"

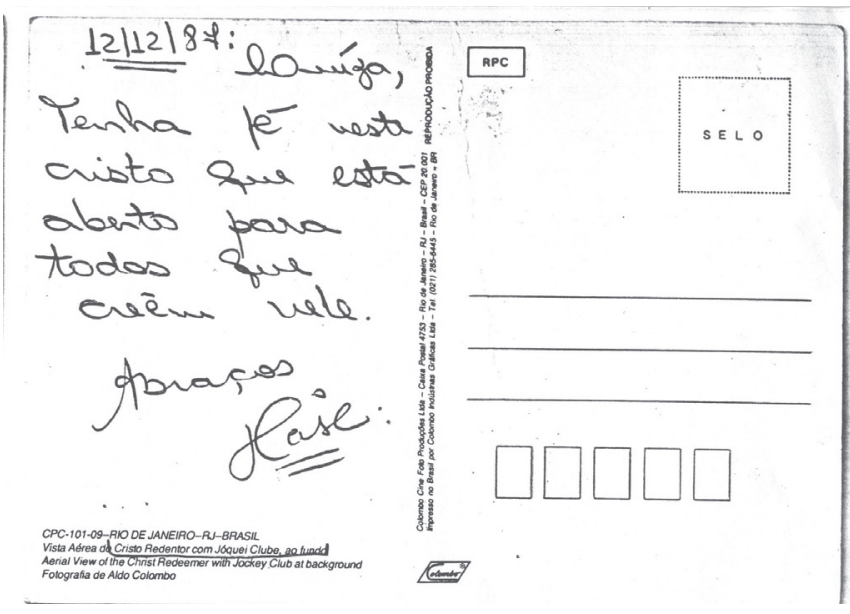

Figura 2 - Verso do cartão "Vista Aeréa do Cristo Redentor com Jóquei Clube, ao fundo"

Os outros quatro textos são assinados por Luiza. A data impressa em dois dos cartões - 25/11/87 - confirma que Luiza Odete se encontrava ainda hospitalizada no Marcílio Dias quando os recebeu. As mensagens expressam: 1) laços de amizade: "com 
muita amizade e carinho da amiga Luiza"; 2) assinalam a passagem pela cidade: "Lembranças do Rio de Janeiro, Luiza" (Imagem 3) ; 3) votos relativos a data comemorativa: "Feliz Natal e Próspero Ano Novo com muito carinho da amiga Luiza"; "Kardec Feliz Natal e um bom Ano Novo com muito carinho, Luiza".

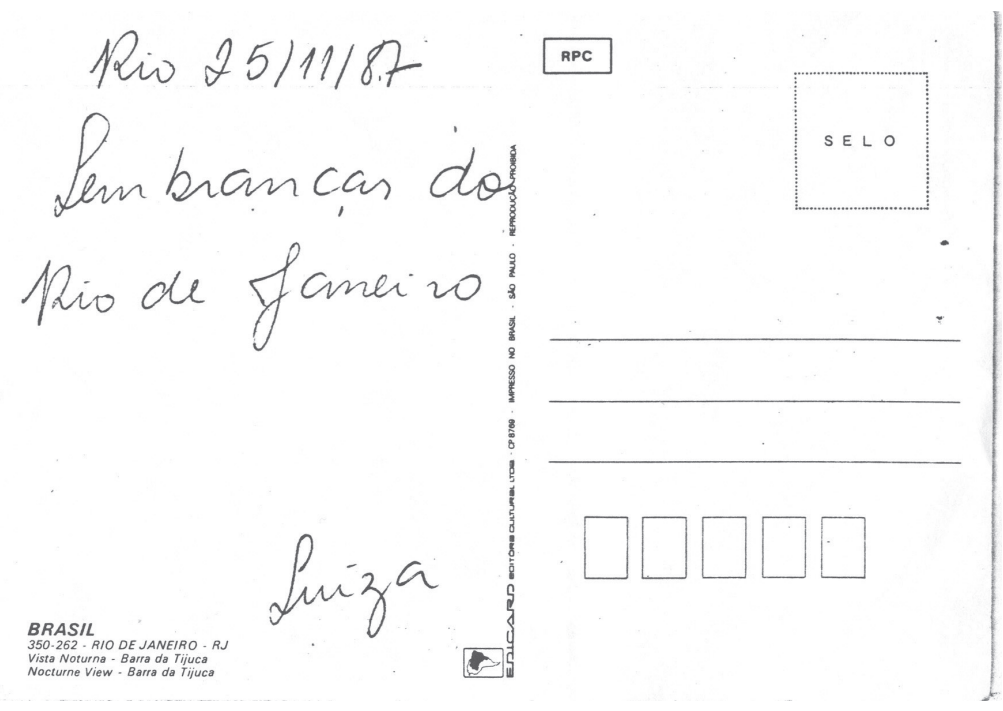

IFigura 3 - Verso do cartão "Vista Noturna - Barra da Tijuca"

Os cartões postais segundo Luíza Odete lhe foram dados como "uma recordação, uma demonstração de afeto pelo fato de ter passado um longo tempo no Rio e nunca ter tido a oportunidade de conhecer a cidade". Ela acha também que as pessoas tinham este carinho porque acreditavam que ela não fosse viver. De fato, a percepção dela não estava equivocada. Um dos médicos, integrantes da equipe do HNMD, descreve a forma como ela chegou no Rio de Janeiro e foi posteriormente transferida para uma enfermaria isolada e blindada, onde permaneceu por mais de dois meses:

Uma paciente como a L. Odete, a irradiação incorporada que ela possuía era tão alta ... Mas que veio (para o Marcílio Dias) com os dados de Goiânia errados. De início nós julgamos que ela não tivesse uma incorporação tão grande, entendeu? Então colocamos numa enfermaria especial, 
também, mas numa enfermaria que não tem blindagem de parede, são paredes como essa. Do lado de fora, o monitor começou a disparar. Todo mundo pensou que fosse defeito do monitor. Não, não foi defeito não, tem alguma coisa aqui dentro. Era ela. Aí ela foi transferida para uma enfermaria blindada. (...) Pela primeira vez para uma enfermaria blindada. (COSTA, Lenine Fenelon. 1996).

As imagens da cidade do Rio de Janeiro _ cidade recortada na perspectiva de construção de uma paisagem turística, convidativa ao passeio e ao prazer _ chegaram até Luíza Odete no momento em que ela se encontrava segregada. O espaço vivenciado naquele momento estava fisicamente blindado e até o piso era revestido por uma lona de plástico para que os fluídos corporais, por exemplo o suor, veículo de contaminação radioativa, não chegassem a outras áreas do hospital. O lugar simbólico também indicava o momento do isolamento e da ruptura. Por um lado porque os laços familiares estavam rompidos _ em suspenso _ pois os filhos haviam ficado em Goiânia e ela tinha o sentimento de que nunca mais poderia reencontrá-los. Por outro lado, os contatos pessoais estavam restritos à equipe interdisciplinar que atuava no Marcílio Dias e o mundo de fora da instituição era mediado por estes profissionais. O HNMD representou para ela uma prisão e esta percepção acompanhou toda a sua permanência no Rio de Janeiro mesmo nos momentos finais de seu tratamento quando, segundo ela diz em entrevista, podia chegar até o quintal do hospital e de lá ver a Rocinha e ouvir o som de tiros que ecoavam de lá. Ou, mesmo quando de ambulância, saía do Marcílio Dias para fazer alguns exames. Nessas ocasiões, ela relembra os trechos da cidade vislumbrados pela janela do carro: as imagens da Barra da Tijuca.

É nesta temporalidade e nesse contexto que a coleção de cartões postais se constitui e enquanto objeto físico, como um artefato, se integra à história pessoal de Luiza Odete. Mas que significados se processam através do ato de guardar esta coleção ao longo de vinte anos (1987-2007)? Como pensar a relação entre a constituição da identidade social de vítima do desastre e a constituição e manutenção do arquivo pessoal?

\section{Os cartões postais como objetos de conhecimento}


Os cartões postais surgem por volta de 1870, quando Emamnuel Hermman, economista austro-húngaro, produziu uma coleção propalada como "um novo meio de correspondência postal" (SOUZA, 2006, p. 2), onde a correspondência era postada sem invólucro protetor. No Brasil, os postais começam a ser veiculados a partir de 1904 (VELLOSO, 2000, p. 114). No início, as imagens impressas se constituíam de gravuras. Com a incorporação da fotografia e das técnicas de reprodução fotomecânica, em 1891, a produção e o consumo de postais foram ampliados (MACHADO, 2002 , p. 5). Esta incorporação da fotografia no objeto cartão-postal acabou interferindo no tamanho das reproduções fotográficas, com o surgimento do formato $9 \times 14 \mathrm{~cm}$ ou $14 \mathrm{~cm} \times 9 \mathrm{~cm}$. (VELLOSO, Op. Cit., p. 114). Os primeiros anos do século $X X$ representam o que os estudiosos desse tema chamam de "anos dourados" ou "idade de ouro" do cartão-postal e o "hábito de colecionar postais depois de utilizá-los como correspondência tornou-se uma prática comum entre as mulheres de famílias das elites e dos setores médios urbanos no Brasil, como uma forma de se conectar com as novidades do mundo da chamada belle poque (Ibid., p.114).

A relação que se estabelece entre o consumidor e o receptor do cartão-postal aponta para a construção de temáticas que posteriormente se constituirão em objeto de estudo de diferentes campos disciplinares. Por um lado, os cartões-postais, enquanto iconografia, são enviados para marcar a experiência vivida em algum lugar distante. No início do século XX, o hábito de viajar era incentivado entre as elites brasileiras e emergia em decorrência do surgimento dos novos meios de transporte, como estradas de ferro e os navios a vapor. Os postais, nesse contexto, indicavam uma distinção de classe através da comprovação visual do 'estive lá". Fontes de recordação de momentos vividos em outros lugares, fora do espaço da vivência cotidiana. Mas eles também permitiam, do lado do destinatário, as viagens da imaginação, as "viagens sem sair do lugar". Ou como diz Velloso (Op.Cit., p. 120):

Os postais, através de suas imagens de cidades e paisagens, permitiam muitas vezes a realização destas viagens apenas no campo da imaginação, já que nem sempre era possível concretizá-las no mundo real; eles democratizavam o desejo de viagem pelo mundo desconhecido, por parte de seus remetentes e destinatários. 
É desta forma que o escritor Mário de Andrade, segundo Moraes $(1993)^{7}$, viaja ao exterior através das imagens de 110 cartões postais recebidos de oitenta remetentes no período entre 1922-1940. Seria então, o mesmo que dizer que Mário de Andrade fez inúmeras incursões ao exterior através de suas "viagens de gabinete". Ou de outra forma, pensar sobre as possíveis construções de lugares que o seu olhar elaborou a partir das visões trazidas pelas fotografias dos cartões postais recebidos.

Por outro lado, enquanto mensagem textual, os cartões postais reafirmam relações de sociabilidade através de uma escrita resumida. Além de manter o destinatário atualizado sobre a viagem que o autor-remetente está realizando, expressa em notícias breves, a escrita postal também assinala e reafirma laços de amizade, de afetividade. É o que nos revela, por exemplo, os 31 cartões postais trocados no período de 1906 a 1908, entre Monteiro Lobato e sua noiva Purezinha (LOBATO, 2006). Através desta correspondência, o leitor tem acesso não só aos aspectos da vida privada de jovens do início do século XX, como também aos cenários da vida cotidiana do interior paulista, como festas e meios de transportes.

Como assinalado por Velloso (Op. Cit., p. 116), a transição do cartão-postal de objeto comercializável a objeto de coleção foi intermediada pela sua utilização como correspondência. Contudo, foram os hábitos de uma determinada época que permitiram a constituição das coleções de cartões postais. Com isto quero enfatizar que o colecionismo de cartões postais ${ }^{8}$, como uma iniciativa pessoal de constituição de arquivos, se institui como uma prática historicamente situada. Hábito que se fomentou no auge da circulação dos postais, no início do século $X X$, e praticado na maioria das vezes por mulheres. É desta forma que estes artefatos são guardados e posteriormente publicados e estudados como no caso da coleção de cartões guardados por Purezinha ou por Josephina Cunha Campos ${ }^{9}$ estudada por VELLOSO(2000). Somente, anos mais tarde, estes artefatos atraem o interesse das instituições museológicas que efetivam em ações a expressão "colecionar cartões-postais é como guardar épocas dentro de um baú" (MASSON; SILVA:1997).

E estes arquivos pessoais e estes baús guarda-memórias foram ao 
longo dos últimos anos abertos por estudiosos vindos de diferentes campos como da História, da Arquitetura, e da Antropologia. Em sua maioria estes estudos focalizam as representações construídas pelas imagens fotográficas reproduzidas nos cartões-postais e privilegiam as análises sobre: 1) as mudanças decorrentes do processo de modernização e as contradições da modernidade a partir da reflexão sobre as paisagens culturais retratadas em cartões-postais do fim do século XIX e início do século XX em São Paulo (FREHSE: 1999; 2000; GERODETTI; CORNEJO, s/d; IMAGENS DA METRÓPOLE, 2004) e no Rio de Janeiro (MACHADO, Op. cit.); 2) as mudanças na socialização das famílias urbanas a partir do projeto modernizador da República (VELLOSO, Op. cit.); 3) o retrato de uma época, como exemplifica o estudo feito por Gilberto Freyre sobre o Ciclo da Borracha em que este estudioso analisou cartõespostais enviados por migrantes (Apud MASSON; SILVA, Op.Cit.).

Posteriormente, com a implantação e consolidação dos estudos de pós-gradução em Turismo, surgem trabalhos que analisam as relações estruturantes dos cartões-postais de paisagens com o objeto a ser vendido, no caso as paisagens como lugares "turísticos" (SOUZA, Op. Cit.). Nesta perspectiva, outra linha de pesquisa parte da interpretação das imagens impressas nos cartões postais para analisar as políticas públicas propostas para o setor turístico na cidade do Rio de Janeiro (SIQUEIRA: 2006; MACHADO, Op. cit.).

Paralelamente ao interesse na interpretação da iconografia dos cartões-postais e do foco na análise do conteúdo da mensagem textual, um outro campo de estudo analisa os postais como um estilo de correspondência e relaciona a sua guarda às relações de gênero engendradas no século XIX. Nesse sentido, Sacramento (2006) em resenha do livro de Michelle Perrot intitulado As mulheres ou os silncios da histria, ao dizer que na cena histórica a memória do privado coube às mulheres, afirma:

Enquanto os homens da burguesia, no século XIX, têm o hábito de colecionar quadros, livros como distinção e sinônimo de suas conquistas econômicas, as mulheres preocupam-se com a roupa branca e os objetos, em uma ânsia de reter sua vidas em 'mil nadas": estojos, nos quais guardam "mechas de cabelo, flores secas, jóias de família", e depois fotografias, croquis e cartões-postais de viagens e outras miudezas. (SACRAMENTO, 2006 , p. 2) 
O colecionamento de cartões-postais se constitui assim, retomando uma expressão de Sacramento (Op. Cit.), como uma das configurações de "espaços de memória" das "mulheres emparedadas", no caso, as mulheres européias burguesas do século XIX. É neste ponto, após uma revisão da bibliografia disponível sobre o tema, que volto aos postais presenteados a Luiza Odete quando ela era paciente interna no HNMD e posteriormente transformados em uma coleção integrante de um arquivo pessoal conservado ao longo de vinte anos.

\section{Emparedamento e evitação: guardando as marcas do sofrimento}

Foi como emparedada que Luisa Odete vivenciou os meses de tratamento no HNMD e nesse contexto é a destinatária dos cartões-postais que colecionou. Eles assinalam laços de amizade e afetividade demonstrados por membros da equipe de profissionais de saúde para uma paciente em situação aguda de contaminação radioativa. As imagens fotográficas do Rio turístico, das viagens turísticas, foram oferecidas pelos remetentes como uma forma de proporcionar uma "viagem da imaginação", uma sugestão para conhecer e sentir estando longe. Contudo, no caso de Luiza Odete, a "viagem de gabinete" como empreendida pelos devaneios de Mário de Andrade se transformou na "viagem do isolamento". O Cristo que abençoa uma expressão de contenção da dor e resignação frente ao sofrimento mais do que uma visita imaginária a um marco turístico da cidade.

A coleção de cartões postais, em 1987, configurava um elo entre dois mundos separados pela radiação, pelo medo e pelo risco da contaminação radioativa. Nesse contexto, o mundo da ordem, por um lado, se expressava através do recorte visual feito pelas pessoas que escolheram entre os vários cartões postais disponívies, aquelas imagens que na percepção do remetente/doador representavam a paisagem urbana do Rio. As imagens trazidas pelas fotografias faziam pensar em praia, liberdade, sol no corpo, luz, espaço aberto, corpos bronzeados, brisa soprando no passeio de barco, 
mar infinito. O mundo da desordem, por outro lado, era aquele evocado pela presença da Luiza Odete: o mundo poluído, o mundo das coisas fora de lugar e por isto entendido como "desastre" e acidente (DOUGLAS, 1966, p. 11-17). Esse corpo "sujo" _ símbolo das consequências decorrentes do risco tecnológico, da pobreza que se nutre das sucatas e da falta de informação _ deveria ser primeiramente higienizado através dos rituais de purificação que aconteciam no HNMD para ser posteriormente re-inserido na sociedade. É esta dualidade entre ordem/desordem; pureza/perigo; confiança/medo; liberdade/segregação que condensa o significado atribuído aos cartões postais como uma dádiva que estabelece a ligação entre dois mundos.

É importante assinalar que o "espaço da ordem" naquele contexto remete ao imaginário constituído sobre a cidade do Rio de Janeiro e o "lugar que ela ocupa como cenário propriciador da sexualidaede e da sedução" e "como as praias da Zona Sul foram sendo construídas na imagem da cidade como lugares de beleza" (HEILBRON, 1999, p. 99). Maria Luiza Heilborn continua sua interpretação afirmando:

(...) a configuração geográfica e o clima tropical da cidade ocupam um papel proeminente. Às características físicas do espaço associadas às temperaturas elevadas em quase todos os períodos do ano é atribuída uma incitação à exibição dos corpos: os espaços abertos oferecidos pelas praias, parques e praças funcionariam como um convite permanente ao desvelamento dos corpos (Ibid, p. 98).

Contudo, enquanto integrada e associada ao "mundo da desordem", a experiência vivenciada naquele momento e naquele lugar por Luiza Odete se configuram como o oposto das imagens trazidas por este imaginário. No lugar do desvelamento e da beleza corporal ela sente e vê no seu corpo as feridas provocadas pela radiação ao mesmo tempo em que passa pela experiência do enclausuramento e da segregação. A vivência do sofrimento impossibilita a transgressão para o empreendimento da "viagem através da imaginação" como aquela empreendida por Mário de Andrade ao olhar as imagens de sua coleção de cartões postais. Os cartões postais, no caso de Luiza Odete, reafirmam a impossibilidade de saída dos limites do prédio do HNMD porque contaminada pela 
radiação. Logo, mais do que as imagens/lugares trazidos pelos cartões postais, é a materialidade desses objetos - desses artefatos - que integram o jogo social como indicadores de uma sociabilidade construída em situação de emparedamento e que coloca de um lado a paciente contaminada pelo desastre e, do outro, os integrantes da equipe de saúde atuando em contexto de emergência radioativa.

No jogo da memória entre o esquecimento e a lembrança, ao longo dos anos o que fica é a memória do sofrimento: a viagem do Rio é a viagem da dor. Nesse sentido, o lugar que se constrói a partir das imagens é o lugar da evitação. Não são as visualidades que são guardadas mas a experiência cotidiana do emparedamento expressa no fato de receber os cartões como objetos sinalizadores da proibição da livre circulação pela cidade. Perguntada se gostaria de visitar o Rio de Janeiro, ela responde que este é a única cidade que não tem vontade de conhecer. Mas aí então a inevitável pergunta: por que colecionar os cartões postais da cidade? Para ela, o significado está em guardar para lembrar do sofrimento e da reclusão. Nesse sentido, o colecionamento, a guarda e manutenção da coleção adquire ao longo de vinte anos a mesma interpretação que ela dá ao fato de ter recusado uma cirurgia plástica para apagar do corpo as cicatrizes deixadas pelas radiodermites em seu pescoço. Emparedada, enquanto mulher, negra, pobre e vítima de um desastre radioativo, estes elementos constituem uma situação de estigma vivida ao longo dos anos pós-abertura da cápsula de césio, em 1987. Carregando na pele as cicatrizes deixadas pela radiação, ela conscientemente guarda a memória corporificada do desastre (SILVA, 2001; 2005). Da mesma forma ela guarda a coleção de cartões postais do Rio de Janeiro como lembrança do lugar que se deve evitar: a dor da radiação. Mais do que guardada _ conservada _, a coleção é "carregada" como as cicatrizes corporais são por ela carrregadas. São pois os cartões-postais como artefatos, mais do que a representação das iconografias que resignificam o Rio de Janeiro como o lugar da evitação. Assim, estes elementos configuram a memória traumática (SILVA, 2007), em que a experiência do desastre ainda não se transformou numa experiência de redenção, e o sofrimento social (KLEINMAN et al.1997, p. IX; SILVA, 2002;2007), através do trauma, continua a se processar. 


\section{Notas}

1 Os dados analisados nesse texto fazem parte do arquivo pessoal da autora e foram coletados com o apoio financeiro da Wenner-Gren Foundation for Anthropological Research (Grant $\mathrm{n}$. 5969 e n. 7046). Uma versão deste trabalho foi apresentada no Simpósio Temático "Histórias, Biografias e Lugares: As narrativas locais e a construção simbólica dos lugares", coordenado pelas professoreas Cintya Maria Costa Rodrigues e Telma Camargo da Silva, no âmbito do III Simpósio Internacional: Cultura e Identidades, organizado pela Associação Nacional de História (ANPUH), e realizado em Goiânia em setembro de 2007.

2 Não foi usado pseudônimo a pedido da entrevistada.

3 Este segundo grupo foi composto por Kardek (marido da Luiza Odete), Maria Gabriela e Edmilson.

4 O HNMD remonta à casa Marcílio Dias, instituição filantrópica, fundada em 1926, por um grupo de esposas de oficiais da Marinha com o objetivo de prestar assistência social e educacional a filhos de praças. Em 18 de setembro de 1972, dá lugar ao Centro Médico Naval Marcílio Dias criado com o objetivo de prestar assistência médica na região do $1^{\circ}$ Distrito Naval e passa a ter função de ensino e pesquisa. Em 8 de fevereiro de 1980 é inaugurado o Hospital Naval Marcílio Dias como Hospital de Base em atendimento às necessidades advindas do Fundo de Saúde da Marinha (FUSMA). Passa então a acumular funções de formação técninca e de aperfeiçoamento dos militares na área de saúde, além de pesquisa médica através de uma Escola de Saúde e de um Instituto de Pesquisas Biomédicas. (Histórico do Hospital Naval Marcílio Dias. Wikipédia. Acesso em: 12 de outubro de 2007).

5 "O programa nuclear paralelo foi impulsionado no Governo do General João Baptista Figueiredo (1979 a 1983), quando a Marinha começou a colocar em prática um plano paralelo para dominar o ciclo do combustível, o "Projeto Ciclone". Na mesma época, a Aeronáutica trabalhava em duas frentes: intensificava suas pesquisas - iniciadas em 1974, no Governo do general Ernesto Geisel - para enriquecer urânio a laser; e levantava uma base, na Serra do Cachimbo, no Estado do Pará, para testar artefatos nucleares. O Exército, por sua vez, projetava um reator a grafite, para obter plutônio". (...) O "primeiro sinal visível" sobre a existência de um programa nuclear paralelo, patrocinado pelas Forças Armadas, foi revelado pelo Jornal do Brasil, na edição do dia 4 de setembro de 1986." (MALHEIROS. T. 1996: 77-78). Esta articulação das Forças Armadas engendrou o Projeto Aramar, base do programa nuclear paralelo, que culminou com a inauguração oficial do Centro Experimental Aramar em março de 1988, em Iperó, no interior do estado de São Paulo. (Ibid. p. 82-84).

6 As imagens reproduzidas nos cartões postais são de propriedade de Colombo Cine Foto Produções Ltda e Edicartd Editora Cultural Itda. Os fotógrafos cujos nomes constam nos cartões são: Carlos O. Sainz e Aldo Colombo.

7 O estudioso Marcos Antonio de Moraes assinala que a única viagem feita por Mário de Andrade ao exterior foi uma escala técnica no Peru. A obra citada, uma edição facsimilar, é uma organização feita por Moraes e apresenta parte do conjunto de postais remanescentes na coleção Mário de Andrade, sob a guarda do IEB-USP. Esta edição apresenta 110 dos 246 postais presentes na coleção.

8 O estudo e colecionismo sistemático de cartões postais se denomina cartofilia. 


\section{Referências}

COSTA, Lenine Fenelon. Projeto - Pesquisa Doutoral de autoria de SILVA, Telma Camargo da. Radiation Illness Representation and Experience: The aftermath of the Goiânia Radiological Disaster. Agência financiadora: Wenner-Gren Foundation for Anthropological Research (grant n. 5969). Entrevista realizada por Telma Camargo da Silva, em março de 1996, na sede da Fundação Leide das Neves Ferreira, em Goiânia.

DOUGLAS, Mary. Introdução. In: Pureza e Perigo. São Paulo: Editora Perspectiva. 1966, p. 11-17.

FREHSE, Fraya. Entre o Passado e o Presente, entre a Casa e a Rua: Tempos e Espaos na Cidade de So Paulo de Fins do Imprio. Dissertação de Mestrado em Antropologia Social. São Paulo, FFLCHUSP, 1999.

Cartões postais paulistanos da virada do século XX: Problematizando a São Paulo 'moderna'. Horizontes Antropolgicos. Porto Alegre, ano 6, n. 13, 2000, p. 127-154.

GERODETTI, Jão Emílio; CORNEJO, Carlos. Lembranas de So Paulo: a Capital Paulista nos cartões-postais e álbuns de lembranças. São Paulo: Solaris Edições Culturais.sd.

HEILBORN, Maria Luiza. Corpos na cidade: sedução e sexualidade. In: VELHO, Gilberto. (Org.) Antropologia Urbana: Cultura e Sociedade no Brasil e em Portugal. Rio de Janeiro: Jorge Zahar Ed., 1999, p. 98-108.

HISTÓRICO do Hospital Naval Marcílio Dias. Disponível em: <Wikipédia>. Acesso em: 12 de outubro de 2007. 
IMAGENS da Metrópole: a história de São Paulo contada por seus cartões-postais. DiverCIDADE. Revista Eletrnica do Centro de Estudos da Metrpole. Número zero, jan./fev./mar. 2004. Disponível em: $\quad<$ http://www.centrodametropole.org.br/zero/divercidade. html>. Acesso em: 13/10/2007.

KLEINMAN, A., at. al. Social Suffering. Berkeley: University of California Press: 1997.

LOBATO, Monteiro.Quando o Carteiro Chegou... cartões postais a Purezinha. LAJOLO, Marisa (Org.). São Paulo: Editora Moderna, 2006.

MASSON, Celso; SILVA, Cândida. Cidades em revista: O museu do Cartão Postal mapeia as mudanças da vida urbana no Brasil. Revista Veja. 22/10.1997. Disponível em: <http://veja.abril.com. br/221097/p_138.html>. Acesso em: 13/10/2007.

MACHADO, Marcello de Barros Tomé. Cartões-Postais: A produção do espaço turístico do Rio de Janeiro na modernidade. Revista geopaisagem. Vol. 1, n. 1, jan.jun., 2002. Disponível em: <http://www. feth.ggf.br/Cart\%C3\%B5es-Postais.htm>. Acesso em: 13/10/2007.

MENESES, Ulpiano T. Becerra de. Rumo a uma 'História Visual. In: MARTINS, José de Souza; ECKERT, Cornélia; NOVAES, Sylvia Caiuby (Orgs.). O imaginrio e o potico nas Cincias Sociais.Bauru, SP:EdusC, 2005, pgs.33-56.

MORAES, Marcos Antonio. (Org.). Tudo est to bom, to gostoso: postais a Mário de Andrade. São Paulo: Edusp / Hucitec, 1993.

SÁ, Antônio Fernando de Araújo. História e memória na Era das Comemorações. In: Vivncia. Natal: Universidade Federal do Rio Grande do Norte. n. 28, 2007, p. 37-55. (Número Temático: Memria. CAVIGNAC, Julie A; VALENÇA, Márcio M. (Orgs.). 
SACRAMENTO, Sandra. Mulheres emparedadas e seus espaços de memória. Revista Estudos Feministas.vol. 14, n. 2. Florianópolis, mar./set., 2006. Disponível em: <http://www.scielo.br/scielo. phd?pid=S0104-026X2006000200022\&scrip=sci_arttext $>$. Acesso em: 13/10/2007.

SIQUEIRA, Euler David de. Para uma etnografia do cartão-postal: destaque para a garota carioca. Trabalho apresentado ao GT 10_ "Antropologia, turismo e responsabilidade social: sentidos e sginificados da diferença", do IV Seminário de Pesquisa em Turismo do MRCOSUL. Caxias do Sul, 7 - 8 de julho de 2006.

SILVA, Telma Camargo da. Política da memória: recompondo as lembranças no caso do desastre radiológico de Goiânia. In: FREITAS, Carmelita Brito de. (Org.). Memria. Goiânia: Editora da Universidade Católica de Goiás, 1998 p. 117-138.

Bodily Memory and the Politics of Remembrance: the aftermath of Goiânia radiological disaster. High Plains Applied Anthropologist. Special Issue: Understanding Disasters and Catastrophies: An Antrhopological Perspective. Colorado. U.S.A. vol. 21., n. 1 p. 40-52. 2001.Spring.

Radiation IIIness Representation and Experience: the aftermath of the Goinia radiological Disaster. Tese de Doutorado em Antropologia. New York, City University of New York (CUNY) Graduate Center, 2002.

As fronteiras das lembranças: memória corporificada, construção de identidades e purificação simbólica no caso d desastre radioativo. In: Vivncia. Natal: Universidade Federal do Rio Grande do Norte. n. 28, 2005, p. 57-73. (Número Temático: Memória. CAVIGNAC, Julie A; VALENÇA, Márcio M. (Orgs.).

Perspectivas antropológicas em desastres: as representações e as experiências engendradas pelo caso de Goi6ania. Palestra 
proferida no I Simpsio Interdisciplinar sobre o Acidente com o Csio 137.Organizado pelo departamento de Ciências Jurídicas da Universidade Católica de Goiás. Goiânia. 04 de setembro de 2007.

As celebrações, a memória traumática e os rituais de aniversário. Revista UFG. Goiânia: UFG. Ano IX, $\mathrm{n} \cong 1$, Agosto de 2007, p. 12-18.

SOUZA, Felipe de Paula. Cartões-postais como divulgadores da imagem turística : o caso de Ilhéus, Bahia. Revista Espao Acadmico, n. 65, Outubro 2006. Disponível em: <http:// www.espacoacademico.com.br/065/65souza_feliope. htm>. Acesso em: 13/10/2007.

VELLOSO, Verônica Pimenta. Cartões-postais: A Família como consumidora-receptora (1905-1912). Anais Museu Histrico Nacional. Rio de Janeiro: Vol. 32, 2000, p. 114-134.

\section{Telma camargo da silva}

Ph.D. em Antropologia pela City University of New York - CUNY, onde defendeu em 2002 a tese Radiation IIIness Representation and Experience the Aftermath of the Goiânia Radiological Disaster. Em 1977, obteve o título de mestre pela École des Hautes Études en Sciences Sociales -EHSS com uma dissertação sobre a a obra de Leandro Gomes de Barros, autor de folhetos de cordel.

tcamargo@uol.com.br, telcamargos@gmail.com 